\title{
THE EFFECTS OF AIR POLLUTANTS FROM THE CEMENT INDUSTRY ON THE HEALTH OF THE KALAMBAINA COMMUNITY, SOKOTO, NIGERIA
}

\author{
MUHAMMAD BELLO MUHAMMAD*1,2, RAHIMAH ABDUL AZIZ ${ }^{1}$ AND YEW WONG CHIN ${ }^{1}$ \\ ${ }^{1}$ Center for Research in Development, Social and Environment, Faculty of Social Sciences and Humanities, Universiti \\ Kebangsaan Malaysia. ${ }^{2}$ Department of Sociology, Faculty of Social Sciences, Usmanu Danfodiyo University Sokoto, Nigeria.
}

*Corresponding author: ibnmuhd80@siswa.ukm.edu.my

Submitted final draft: 28 July $2020 \quad$ Accepted: 30 August 2020

http://doi.org/10.46754/jssm.2021.06.017

\begin{abstract}
This study examines the effects of air pollutants from the cement industry on the health of the Kalambaina community in Sokoto, Nigeria. The main objectives of the study are to look into the types of diseases caused by the air pollutants from the Sokoto cement industry and examine how cement pollution negatively impacts the health of the people of the Kalambaina Community. The survey method was adopted and a sample of 195 respondents was taken to represent the Kalambaina community. A combination of cluster sampling, purposive and systematic sampling techniques was used. A personal faceto-face structured questionnaire was used to collect the data from the respondents and the analysis was done using Statistical Package for Social Sciences (SPSS). To further support the findings, $10 \mathrm{key}$ informants were interviewed. They were the traditional and religious leaders of the four villages chosen for the study, as well as the health and environmental personnel of the Kalambaina community. The findings reveal that cement pollution has negatively impacted the health of the people of the Kalambaina community, causing various maladies, endangering their health and thus, stagnating their development. Adequate measures were not taken by the government to address the problem. Subsequently, some community members have chosen to migrate to safer places. Proper environmental laws and social policies must be implemented by both the government and the cement industry to curb this health crisis and enhance environmental sustainability.
\end{abstract}

Keywords: Cement dust, industry, health, environment, sustainability.

\section{Introduction}

The World Health Organization stated that 7 million people worldwide are killed annually due to the inhalation of particle dust linked to air pollution, with 9 out of 10 people breathing air containing high levels of pollutants (Martínez-Bravo \& Martínez-del-Río, 2020). Epidemiological investigations confirmed that more than 500,000 Americans die due to dust particle every year from cardiopulmonary infections related to breathing fine molecule air pollution (Rani et al., 2011). An examination by the University of Birmingham has demonstrated a strong relationship between pneumoniarelated deaths and air pollution from vehicles. Overall, more deaths every year are connected to air pollution than car crashes. In the Clean Air For Europe (CAFE, 2005) Programme, studies estimate that 310,000 Europeans die yearly due to dust from air pollution. The common reasons for deaths include asthma, emphysema, lung and heart diseases, and respiratory hypersensitivities. In more recent years, a report by the European Environment Agency (2018) stated that 518,700 people died due to the three most harmful pollutants for human health, fine particulate matter, nitrogen dioxide and ozone.

Air pollutants are major environmental health hazards to people, particularly for youngsters, whose respiratory organs are still developing (Liu \& Zhang, 2009). Introduction to some air pollutants, e.g., sulfur dioxide, nitrogen oxides, and particulate matter, is a known hazard factor for intense and interminable respiratory infections (Kagawa, 1985; Balmes et al., 1987; Kampa \& Castanas, 2008). Such different ailments include myocardial infection, ischemic stroke, and cardiopulmonary sickness (World Health Organization, 2004). The cement industry has a negative impact on the air quality 
of the environment in which a community is located. The key air pollutant emissions from the cement industry are nitrogen oxides, sulfur dioxide and particulate matter. The cement industry and other manufacturing plants' emissions are some of the main contributors to poor air quality, especially in urban developed areas of developing countries (Air Quality Resources, 2011).

Industrialization, as a process, cannot be comprehended without referring to people living in these societies. In other words, there is a close relationship between the society and its environment from one point of view and industries on the other. People occasionally abuse their social and physical environment to enhance and improve their lives. When an industry is established in a location to produce certain products, it brings positive changes to the economic existence of the people living around the environment in the form of jobs and different business enterprises. On the other hand, the activities of the industries also carry negative impacts on the environment that affect the economic development of the community, for example, pollution, be it air, water and land, which have devastating impacts on humans, animal health and nature itself (Muhammad et al., 2018a; 2018b).

Cement pollution and its negative impacts on the general human health include coughing fits and mucus generation, chest snugness, impedance of lung functions, obstructive and prohibitive lung sicknesses, pleural thickening, fibrosis, emphysema, lung nodulation, pneumoconiosis and carcinoma of the lung. They also include susceptible responses that meddle with breathing: allergic responses that bring about breathing issues, from basic runny noses to hazardous respiratory diseases (Valavinidis, 2008). The objectives of this study are to investigate the types of diseases caused by air pollutants from the Sokoto cement industry and to examine how cement pollution negatively impacted the health of the people of the Kalambaina community in Sokoto, Nigeria.

\section{Air Pollution in Nigeria}

The health impacts brought about by air pollution may include difficulties in breathing, wheezing, coughing and exacerbation of existing respiratory and heart conditions. These negative impacts can result in increased emergency clinic visits, consultancy on medicine use and in terminal conditions, and may lead to sudden death. The impact of poor air quality on human health is enormous as it mainly affects the body's respiratory and cardiovascular systems. Responses to air pollution rely on the kind of pollutants an individual is exposed to, the level of introduction, the person's health status and hereditary factors (Davis, 2002).

The main objective organs attacked by air pollution are those in the respiratory system, from the nasal pit to the bronchi, which is the entry point for air, and the bodily fluids covering the mucous epithelium. They also include the aviation route of trachea and the bronchi, which are furnished with cilia to dispose remote substances. Additionally, there are the alveolar macrophages of phagocyte in the alveolar of the lungs, which exchanges carbon dioxide for oxygen. Of the air pollutions breathed in, the bigger particulate matter is trapped in the nasal pit. Suspended particulate matter, which is estimated to be $10 \mu \mathrm{m}$ or less in width, go through the nasal pit to arrive at the trachea, as well as the alveolar. Of the gas substances, sulfur dioxide, which is solvent in water, is ingested fundamentally in the upper aviation route, causing incessant bronchitis or asthma (Gopinath, 2018).

Ozone, nitrogen oxides and other insoluble gas substances, meanwhile, advance somewhere down in the lungs, causing asthma, constant bronchitis or potentially pneumonic emphysema. Furthermore, carbon monoxide may contaminate the hemoglobin in the blood alveolar, exasperate the transportation of oxygen by the blood as its molecules consolidate with hemoglobin more effectively than oxygen. In situations where the air is seriously polluted, old people and patients with certain incessant base maladies face risk of death by intense bronchitis (Buchanan \& 
Horwitz, 2010). From the literature above, it can be concluded that air pollution is hazardous to human respiratory organs.

People use their five faculties of sight, hearing, smell, contact and taste as methods for obtaining data from the outside world. The sense of smell attempts to distinguish scents and, alongside taste, might be known as a substance sense. Smell has capacities that react to a set number of compound substances (which are substances with scents). People, for the most part, depend on their faculties of sight and hearing to live, although sight and hearing are very much created. Smell is, by examination, and to some degree, a crude sense. The smell of spoiled food and consumed drinks tend to warn an individual of the looming risk. And based on an individual's way of life, pleasant aromas can be found in scent, beautifying agents, flavors, etc, making the sense of smell a fundamental part of existence. If one thinks about existence without the sense of smell, it captures exactly how significant the sense is (Agapito, 2013).

Epidemiological examinations show that airborne molecules enter the nasal depression alongside breathed-in air, and land at the olfactory film on top of the hole by travelling along the nasal aviation route, where they break down in the mucous olfactory layer. The olfactory film contains olfactory organs (Bowman's happy) focused with olfactory cells, which are sense receptor cells. The olfactory organ's hairs reach out from the length of the olfactory cells through the mucous, and the tip of the cells (the olfactory smell vesicle), likewise, gets into the mucous layer. Small particles that enter the mucous hit both the olfactory organ's hairs and olfactory little vesicle and energize the layer along these lines, transmitting as drive (an electrical sign) to the olfactory cells. The olfactory nerve, which distends from the cells, enters the olfactory cylinder, which is the essential pivot to the immediate feeling of smell. In addition, it is transmitted to the cerebral cortex, where the idea of the smell is recognized (Buchanan \& Horwitz, 2010).

\section{Effects of Cement Pollution on Human Health}

Prior respiratory conditions add to the seriousness of hypersensitive impacts on the respiratory system. The accompanying respiratory maladies underneath come about because of breathing in air pollutants:

i. Emphysema: In emphysema, the alveolar tissue is halfway pulverized, and the rest of the alveoli are debilitated and grow in size. The bronchioles breakdown results from the exhalation and inhalation of air in the alveoli. After some time, this procedure debilitates the capacity to trade particulate matter, oxygen and carbon dioxide within the respiratory system, prompting breathing challenges. Emphysema is a noncoterminous ailment that is the result of various variables, including a hereditary inclination to the condition, exhaust clouds, tobacco smoke, and disease (Valavinidis, 2008).

ii. Lung malignant growth: Studies of the American Cancer Society associate particulate presentation to lung disease. For instance, if the centralization of noticeable particles increases by just $1 \%$, the danger of building up a lung malignancy increases by $14 \%$. Furthermore, ultrafine particles infiltrate further into the lungs (Krewskhi et al., 2004; Pope et al., 2002).

iii. Pneumonia: Pneumonia is an irritation and infection of the lungs. Even though pneumonia is an exceptional risk for older people and those with perpetual sicknesses, it can strike youthful, strong people as well. In irresistible pneumonia, microbes, infections, growths or different life forms attack the lungs, prompting irritation that makes it difficult to relieve. Pneumonia can influence either one or two lungs. Infection of the two lungs is termed as twofold pneumonia (Mannucci, 2019).

iv. Tuberculosis: Tuberculosis is brought about by a bacterium that attacks the lungs and other body tissues. If infection in the lungs is left untreated, it obliterates the lung tissue. Previously, anti-infection agents 
have brought tuberculosis under control. However, recently, new anti-microbialsafe strains of the tuberculosis bacterium have emerged. These new strains presents a significant issue to the medical community (Bateman \& Carr, 2008).

v. Cough: A cough is an abrupt and frequently redundant reflex that clears the enormous breathing sections from discharges, aggravations, remote particles and organisms. The cough reflex comprises three stages: an inward breath, a constrained exhalation against a shut glottis, and a savage arrival of air from the lungs following opening of the glottis, normally joined by a sound (Chung \& Pavord, 2008). Coughing can happen intentionally, as well as automatically. Coughing might be brought about by air pollution, including tobacco smoke, particulate matter, aggravation gases, and clamminess in the home (Goldsobel \& Chipps, 2010).

vi. Wheeze: Wheezing is a sharp whistling sound while relaxing. It happens when wind passes through limited breathing cylinders. There may be different reasons for wheezing, such as asthma, bronchitis, breathing of any outside substance or residue, and so on (David et al., 2010). The bronchial tree comprises cylinders that convey air into the lungs. When these cylinders get polluted, they swell and accumulate bodily fluid structures. This makes it difficult for an individual to relax. The individual may cough up bodily fluid and wheeze (Mannucci, 2019).

vii. Asthma: Asthma is a condition where the wind stream through the lungs may be obstructed by swelling, muscle contraction, and bodily fluid in the lower aviation routes. These scenes of fractional blockage, called asthma "passages" or "attacks," can be activated by dust, pollutants, smoke, cold air, or diseases. The impacts of poor air quality on human health are numerous, yet mainly affect the body's respiratory and cardiovascular systems (Valavinidis, 2008).

\section{Gastro-Intestinal Diseases Brought about by Cement Dust}

Investigations into the processes of cement production reveal the relationship between pollution and health hazards. Additionally, expanding proof shows how negative impacts of cement pollution cause gastrointestinal infections. In the stomach, pollution causes stomach throb and diseases. Oral pits, mechanical injuries, mucosal irritation, loss of tooth surface, periodontal maladies, dental caries, dental scraped spot, liver diffusion, swelling and multiplication of sinusoidal (hepatic) lining cells, sarcoid sort granulomas, perisinusoidal and entrance fibrosis and hepatic injuries all happen in the gastrointestinal system (Valavinidis, 2008).

Nitrogen oxides have a wide range of health and ecological effects due to the different mixes and subordinates of the group, which includes nitrogen dioxide, nitric corrosive, nitrous oxide, nitrates, and nitric oxide. Like sulfur dioxide, nitrogen oxides respond to water and different mixes to produce different acidic mixes. When these acidic mixes are stored in the world's surface, they can debilitate the water nature of various water bodies and ferment lakes and streams. Fermentation (low pH) and the substance changes make it hard for some fish and other oceanic species to endure, develop, and reproduce. Corrosive downpours can likewise harm backwood biological systems by harming plant tissues (EPA, 2014).

Nitrogen oxide is an ozone-harming substance and it amasses in the environment with other nursery gases, causing a progressive increase in the world's temperature. This will prompt an unnatural weather and environmental change. Nitrogen oxide and unpredictable natural mixes respond in the environment to the sight of daylight to produce ground-level ozone, which causes brown haze in urban communities and provincial territories. This ground-level ozone, when inhaled, causes respiratory sickness and other medical issues (EPA, 2014). Nitrogen dioxide influences body capacities, for example trouble in breathing, incessant 
lung infections, interminable aggravation and irreversible auxiliary changes in the lungs, rehashed presentation, untimely development of the lungs and other respiratory ailments. The central unsafe impacts of VOCs are lethality, conceivable commitment to brown haze by means of photochemical responses in the environment, and conceivable commitment to the "nursery impact", resulting in a worldwide temperature alteration (Woodard, 2001).

\section{Materials and Methods}

The survey method was adopted and a sample of 195 respondents was taken to represent the Kalambaina community using a combination of cluster sampling, purposive and systematic sampling techniques. A personal face-to-face structured questionnaire was used to collect the data from the respondents and the analysis was done using Statistical Package for Social Sciences (SPSS). To further support the findings, 10 key informants were interviewed. They were the traditional and religious leaders of the four villages chosen for the study, as well as the health and environmental personnel of the Kalambaina community.

\section{Location of Study}

The general population of the Wamakko Local Government Area is 179,246 (NPC, 2006),

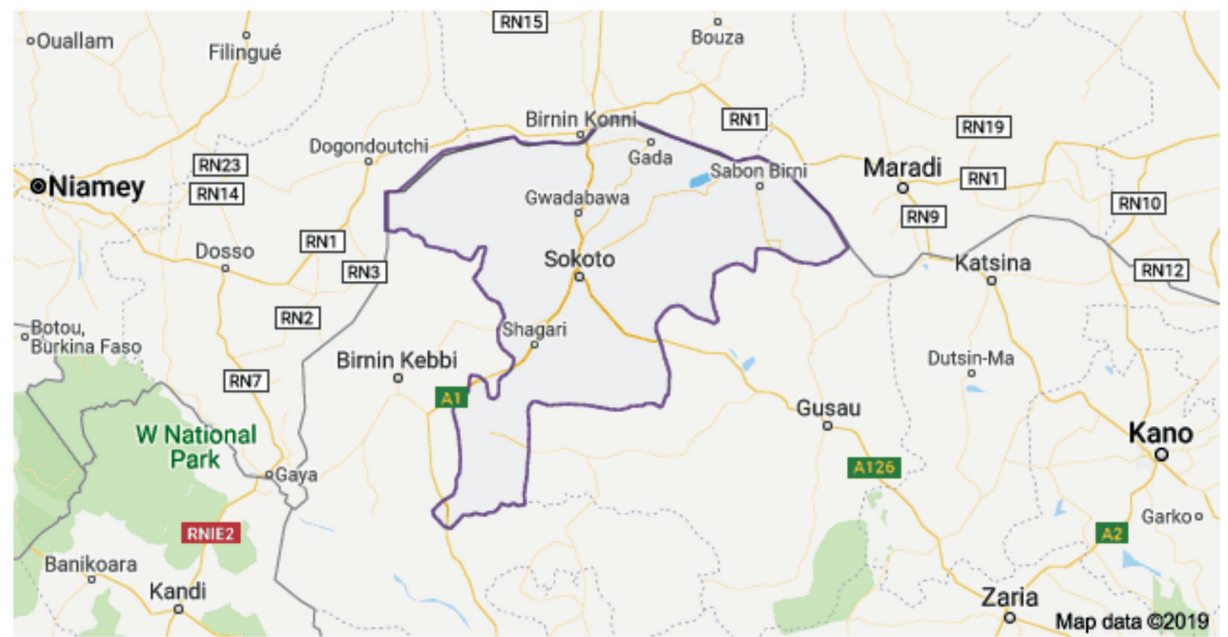

Figure 1: A map of the study area in Sokoto state, Nigeria

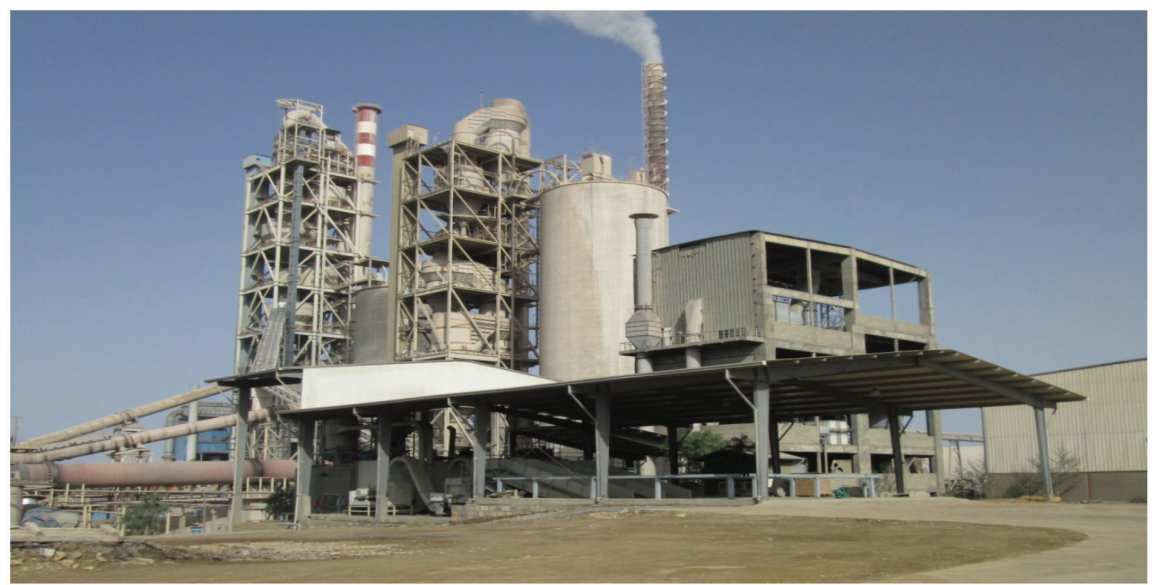

Figure 2: A Sokoto cement factory 


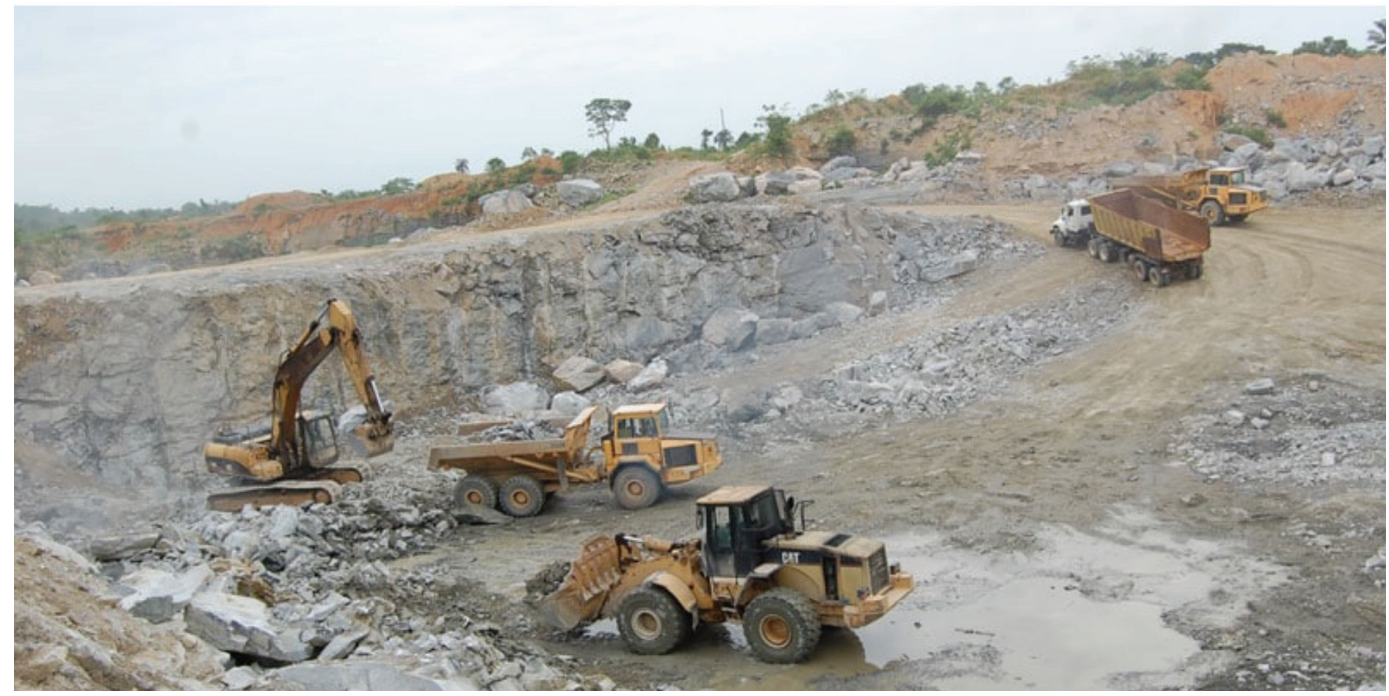

Figure 3: A limestone quarrying site at Kalambaina community, Sokoto, Nigeria

consisting of various communities, in which Kalambaina holds a population of 18,320 and Nasarawa Arkilla, 11,110. Kalambaina consists of eight villages (Gidan Gamba, Gidan Bailu, Gidan Maituta, Gantsare, Gidan Baduwa, Girabshi, Gidan Kuka, and Fandirma). Considering the population of the Kalambaina Community in Sokoto State, the size is too large for the researchers to easily manipulate. Hence, the researchers needed to take a specific sample of the total population. In this regard, 200 respondents were selected and, therefore, served as the respondents of the study. However, four villages were chosen from the eight villages and to ensure that the sample to be drawn is representative of the population in the four villages, 50 respondents were drawn from 150 houses in each village among the Kalambaina community. The target population were males aged 21 and above. The study is more interested in men in spite of the importance of women or their role in society. Men have more control over resources, especially material and cultural resources. Men in the Hausa society are also responsible for decision-making and provision of funds for healthcare and other services in the communities studied.

This study involved the use of primary and secondary data sources. The primary source involved collecting data directly from the respondents (the Kalambaina community) using personal face-to-face structured questionnaire. The secondary data sources included official documents from the cement company and other government agencies.

The content validity of the instrument was determined by experts in research at Universiti Kebangsaan Malaysia and the Ministry of Health and Environment, Sokoto, who looked at the technique and coverage of the specific objectives of the study. The experts recommend the areas to be corrected, and the recommendations were incorporated, which increase the validity. It was tested for validity by pre-testing, through a pilot study carried out twice among 120 members of the Nasarawa community. After that, a Cronbach's alpha value of 0.78 was obtained using Statistical Packages for Social Sciences (SPSS) version 23, which signified the instrument's reliability.

During this research, a multistage sampling technique was adopted, and a cluster sampling technique was used in dividing the whole area into eight villages and a purposive sampling technique was used in selecting four villages in the community, where each was identified as a cluster. Within the cluster, a systematic sampling technique was applied in the process 
of selecting the samples of this research. Each of the four villages of the Kalambaina community constitute of about 150 houses, in which every third house was selected on each street and the head of the household was administered with the questionnaire. The questions in the questionnaire were the same for all respondents and contained open-ended and close-ended questions. The open-ended questions gave the respondents greater flexibility to express themselves with the questions and gave them the freedom to decide the detailed aspects and the length of their answers. The close-ended questions gave them the chance to choose their answers only from predetermined options. This helped minimize the risk of misinterpretation and permitted easier tabulation and interpretation of data by the researchers.

To further support the quantitative data and analysis, ten key informants were interviewed. Two key informants each were interviewed from the four selected villages of the Kalambaina community. The informants were traditional and religious leaders. This was since each village has traditional and religious leaders playing vital roles in the villages. The remaining two informants interviewed were the environmental and health personnel of the Kalambaina community. They provided us privileged information that cannot be obtainable from other residents.

The data collected from the survey was analysed using Statistical Packages for Social Sciences (SPSS) version 23. The data were analysed with the help of frequencies and percentages, which are presented in the form of tables, pie chart and cross tabulations. Most of the respondents were busy and, as such, repeated attempts must be made to make them spare their time and attend to the questionnaire given to them. This explains why some of the questionnaire could not be retrieved from the respondents up to the compilation level of the study. The return rate was 195 out of the 200 questionnaire distributed. To further support the quantitative analysis. The information collected from the ten key informants interviewed was subjected to qualitative analysis through content analysis. The recorded audio data were sent to an expert transcriber with experience in qualitative studies, conducted in the academic sector, who was accustomed to handling sensitive information with confidentiality. Moreover, the transcriber was provided with background information on the subject before the transcription process to aid understanding and grasp of the subject matter. The transcriber ensured satisfaction with the content, quality and the clarity of the audio recordings. The conduct of the analysis was done manually by listening to the transcription repeatedly and going over the notes taken during the interview to accustom with the collected data. The produced transcribed word document was crosschecked with the audio outputs to ensure correctness of the transcription. This brought out the thematic views of the respondents through verbatim quotations. Code and sub codes, and matrices were developed to facilitate easy analysis of the qualitative data.

\section{Results and Discussion}

Although there were various air pollutants, some pollutants were, however, identified and widely associated with air pollution, especially with emissions from industrial activities, automobiles and other sources of pollutants that cause harm to both man and his environment. The Sokoto Cement Company alone emits about 5 metric tonnes of air pollutants into the air for every 110 to 115 metric tonnes fed into the kiln per hour, if the electrostatic precipitator machine is not functional, which makes the pollution rate level 10 and above on the air quality health index table (Sokoto Cement Processing Unit, 2019), which is hazardous to human health and crop yields.

Table 1 shows the Sokoto Cement Company's air quality control unit, emission point, pollutants, emission rate and control devices. The cement kiln itself had been designated as the best available control technology (BACT) for the control of sulfur dioxide, or $\mathrm{SO}_{2}$. The highly alkaline conditions of the kiln system enable it to capture up to 
Table 1: The Sokoto Cement Company, Air Quality Control Unit

\begin{tabular}{clcl}
\hline $\begin{array}{c}\text { Emission Point } \\
\text { Kiln System }\end{array}$ & Pollutants & Emission Rate Percent & \multicolumn{1}{c}{ Control Device } \\
\hline & Particulates & $4-18$ & Dust Collectors: Reverse Air \\
& $\mathrm{SO} 2$ & 99.5 & Precipitator \\
\hline
\end{tabular}

Source: Sokoto Cement Processing Unit, 2019

95\% of the possible $\mathrm{SO}_{2}$ emissions. However, if sulfide sulfur (pyrites) is present in the kiln feed, this absorption rate can decline to as low as $50 \%$ (Sokoto Cement Processing Unit, 2019).

The cement oven itself has been assigned as the best accessible control innovation (BACT) for the control of $\mathrm{SO}_{2}$. The exceptionally antacid states of the furnace framework empower it to catch up to $95 \%$ of the conceivable $\mathrm{SO}_{2}$ outflows. Be that as it may, if sulfide sulfur (pyrites) is available in the furnace feed, this assimilation rate can decrease to as low as half (Sokoto Cement Processing Unit, 2019). As it is presently realized, even low degrees of air contamination can trigger inconvenience for the delicate populace, and the file underneath has been created as a continuum: The higher the number, the more noteworthy the health hazard and the need to play it safe. The file portrays the degree of health danger related to this number as "low", "moderate", "high" or "very high," and recommends steps that can be taken to diminish introduction.

Table 2 shows the different levels of air quality health index and the health risks. When the air quality health index levels are within 1 to 3 , the health risks are low, and the risk population can enjoy usual outdoor activities and the general population have the ideal air quality for outdoor activities. From levels 4 to 6 , the health risk is moderate, and both the risk and general population should consider reducing or rescheduling strenuous activities outdoors if they experience symptoms such as coughing, and throat irritation, etc. At levels 7 to 10 , the health risk is high. The risk and

Table 2: Air quality health index levels

\begin{tabular}{|c|c|c|c|}
\hline $\begin{array}{c}\text { Health } \\
\text { Risk }\end{array}$ & $\begin{array}{l}\text { Air } \\
\text { Quality } \\
\text { Health } \\
\text { Index }\end{array}$ & \multicolumn{2}{|c|}{ Health Messages } \\
\hline & & For risk populations & *general populations \\
\hline Low & 1-3 & Enjoy your standard open-air activities. & Ideal air quality for outdoor activities \\
\hline Moderate & 4-6 & $\begin{array}{l}\text { Consider lessening or rescheduling } \\
\text { strenuous exercises outside on the } \\
\text { off-chance that you are encountering } \\
\text { symptoms. }\end{array}$ & $\begin{array}{l}\text { No need to alter your typical open- } \\
\text { air exercises, except if you experience } \\
\text { symptoms, such ashacking and throat } \\
\text { disturbance. }\end{array}$ \\
\hline High & $7-10$ & $\begin{array}{l}\text { Reduce or reschedule strenuous } \\
\text { exercises outside. Kids and the elderly } \\
\text { ought to take it easy. }\end{array}$ & $\begin{array}{l}\text { Consider diminishing or rescheduling } \\
\text { strenuous exercises outside on the off-chance } \\
\text { that you experience symptoms, such as } \\
\text { hacking and throat disturbance. }\end{array}$ \\
\hline Very high & Above 10 & $\begin{array}{l}\text { Avoid strenuous exercises outside. } \\
\text { Youngsters and the elderly ought to } \\
\text { maintain a strategic distance from open- } \\
\text { air physical exertion. }\end{array}$ & $\begin{array}{l}\text { Reduce or reschedule strenuous outdoor } \\
\text { exercise activities, particularly in the event } \\
\text { that you experience symptoms, such as } \\
\text { hacking and throat aggravation. }\end{array}$ \\
\hline
\end{tabular}

Source: Sokoto Cement Processing Unit, 2019. 
general population should reduce or reschedule strenuous activities outdoors. Children and the elderly should take outdoors activities easy. Levels above 10 indicate very high health risk. Populations at risk should avoid strenuous activities outdoors. Children and the elderly should avoid outdoor physical exertion, and the general population should reduce or reschedule strenuous activities outdoors, especially if they experience symptoms such as coughing and throat irritation.

Air pollution is an important ecological health risk to people, particularly for youngsters, whose respiratory organs are still developing (Liu \& Zhang, 2009). Exposure to air pollutants, e.g., sulfur dioxide, nitrogen oxides, and particulate matter, is a known hazard factor for intense and ceaseless respiratory infections
(Kagawa, 1985; Balmes et al., 1987; Kampa \& Castanas, 2008), alongside different illnesses, such as myocardial infection, ischemic stroke, and cardiopulmonary infection (World Health Organization, 2004).

Air pollution caused by cement dust has the most negative impact on the health of the Kalambaina community. Particulate matter and sulfur dioxide coming from cement production causes respiratory diseases that lead to hospital admissions. These diseases include lung and heart diseases. Numerous studies show that these pollutants cause minor and major diseases. Furthermore, the Kalambaina Community Healthcare Center at Wakeji has provided the records of patients and types of diseases they suffered between January 2016 and November 2018 caused by cement dust as follows:

Table 3: Records of patients and types of diseases suffered between Jan. 2016 to Nov. 2018

\section{Health Problems}

Respiratory diseases: Asthma, wheezing, coughing and running nose

Gastrointestinal diseases: Stomachache and diarrhea

Other disease: Skin irritation and watery eyes

Total

Source: Medical Records, Wakeji Health Care Center, 2019

\section{No \\ 10298}

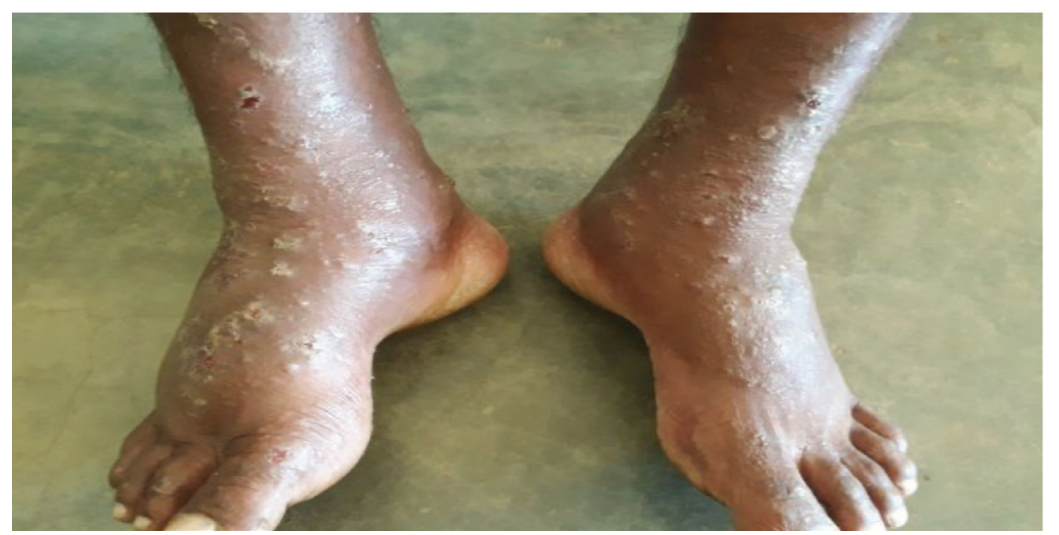

Figure 4: Picture of skin rashes due to cement dust among people of the Kalambaina community in Sokoto 
These diseases hinder them from interacting and participating fully in society and, if not treated, can lead to death. Table 4 shows the types of major health issues faced by the community, in which $96(42.0 \%)$ respondents said they suffered from asthma due to the cement dust they inhaled, while 68 (31.2\%) respondents said that they had coughing fits due to cement dust. However, only $31(26.8 \%)$ respondents experienced skin itching. This shows that the activities of the cement industry emit cement dust that triggers asthmatic attack in the majority of the respondents, compared with any other health problems. Clinic records from Wakeji shows a high number of residents among the Kalambaina community partronising the clinic with various respiratory infections. About 20 to 30 patients each week receive drugs from the clinic (Wakeji Clinic Records, 2019).

The impacts of poor air quality on human health are far reaching, but it principally affect the body's respiratory and cardiovascular systems. Diseases and symptoms, such as chest pain, coughing fits, and eye problems, in the villages affected by cement dust are likely to be caused by cement dust. Indeed, the higher percentage of related diseases occurs near the source of pollutants. A relative risk ratio assessment indicates that the exposed subjects are 7.5 and 22.5 times more likely to develop the diseases during the follow-up period, compared with the unexposed subjects (Yhdego, 1992). There may be various causes of wheezing, such as asthma, bronchitis, and breathing of any foreign substance or dust, etc (David et.al., 2010). This further shows the impacts of cement dust on the health of the community, as it can also be seen in the Key Informants Interview
(KII) responses below from the health personnel, as well as traditional and religious leaders of the community.

"Well, the activities of the company emit cement dust into the air in the form of particulate matter, causing air pollution, which causes irritation of the throat, skin and eyes, also triggering asthma and coughing." (KI 10)

"...mostly particulate matter and sulfur dioxide constitute the pollutants in the air within the Kalambaina community, which comes from the cement company." (KI 10)

"...irritation of the throat as the major symptom of coughing, triggering of asthma is common due to inhalation of polluted air, which causes difficulty in breathing, skin and eyes itching are common due to the cement dust." (KI 10)

"Due to our proximity to the cement company and exposure to the cement dust, we suffer from cough, skin irritation, asthma, running eyes, these health issues affect us badly." (KI 3)

"The cement industry emits cement dust, which makes us suffer from cough, skin irritation, asthma, running eyes. These health issues affect us badly." (KI 6)

"Our community suffers difficulty in breathing due to polluted air and this affects our health adversely causing cough, irritation of both the throat and eyes." (KI 4)

Table 4: Types of major health problems in the community

\begin{tabular}{lcc}
\hline Health Problems & No & Percent (\%) \\
\hline Skin Itching & 31 & 26.8 \\
Cough & 68 & 31.2 \\
Asthma & 96 & 42.0 \\
\hline Total & 195 & 100.0
\end{tabular}

Source: Field Survey, 2019 
The period of these health problems faced by the villages was also discussed. Table 5 shows that $100(54.1 \%)$ respondents said they have been experiencing health problems for more than 40 years, while $59(31.3 \%)$ respondents have been experiencing health problems for more than 20 years. The Sokoto cement industry dates back to the early 1960s, when traces of limestone deposits were discovered in Kalambaina. The company was established and incorporated on the $13^{\text {th }}$ of July 1962, and commenced production in 1967. This shows how the activities of the cement industry have been causing health problems for more than 52 years to the village population.

This can also be seen in the Key Informants Interview (KII) responses below from the health personnel in the community.
"The patients come in at different stages, exhibiting different ailments as mentioned earlier, which is the result of long exposure to air pollutants from the activities of the cement company, which can be treated." (KI 10)

"...the patients are examined, and appropriate drugs are administered, ranging from cough syrups, tabs, skin lotion, eye drops and inhalers, etc." (KI 10)

Figures 5 shows that $45 \%$ of the respondents' health statuses to be fair, and $10 \%$ of the respondents have poor health, bringing the total percentage of respondents having health problems to $55 \%$. This implies that most of the respondents are affected by cement pollution, leading them to suffer from various diseases.

Table 5: Period of health problems in the community

\begin{tabular}{lcc}
\hline Period Health Problems (Years) & No & Percent (\%) \\
\hline 20 & 59 & 31.3 \\
30 & 36 & 14.6 \\
40 & 100 & 54.1 \\
\hline Total & 195 & 100.0 \\
\hline
\end{tabular}

Source: Field Survey, 2017

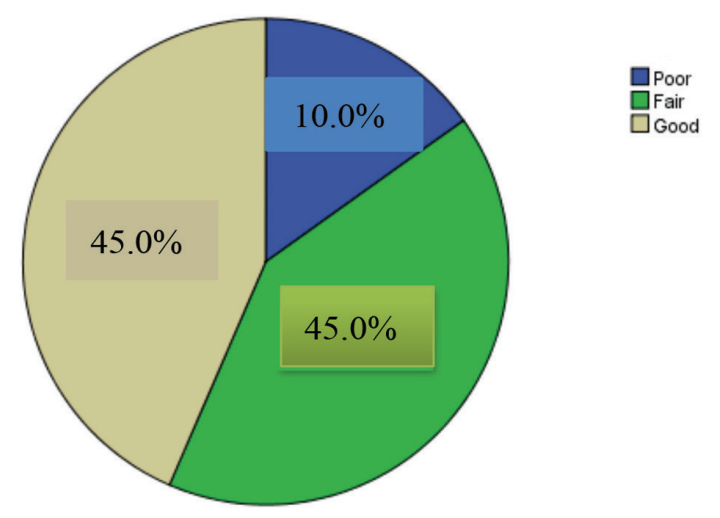

Figure 5: Health statuses of the respondents Source: Field Survey, 2019 


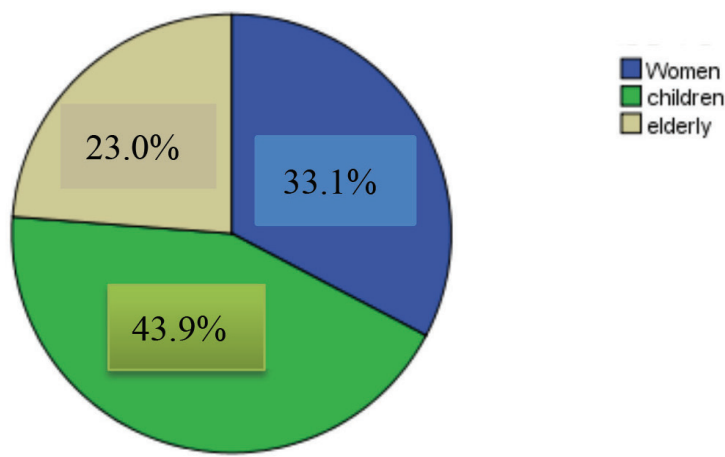

Figure 6: Vulnerable health risk groups affected by cement pollution Source: Field Survey, 2017

The group of people mostly affected by health problems in the community was also obtained. Figures 6 shows that 161 (43.9\%) respondents said children experienced more health problems compared with women at $121(33.1 \%)$ respondents and the elderly at 88 (23.0\%) respondents. This shows how children are mostly affected due to their vulnerability. Also, their immature organs cannot resist the impact of the cement dust from the activities of the cement industry in the villages of the Kalambaina community.

The health impacts brought about by air pollution may include difficulty in breathing, wheezing, coughing and exacerbation of existing respiratory and cardiovascular conditions. Likewise, the impacts of particulate issues on human health have been noted by various researchers (Ossai, et al., 1999; Okecha, 2000; Efe, 2005), which affirmed that the high rates of respiratory illnesses, punctuated by the expanded particulate matter fixations, were experienced by inhabitants of most urban regions. In particular, Efe $(2005,2006)$ noticed that residents around processing industries, business territories, traffic-obstructed zones and high-pollution locations in the Warri city were the most affected, with more than $15 \%$ of the cases recorded among babies and children in Benin city, Ibadan, Kano and Port Harcourt, among others.

Table 6 shows the cross tabulation of the age and health needs of the respondents. A total of 141 respondents said they have health needs, while the remaining 54 respondents said they did not. This shows that the majority of the respondents were affected by the cement dust, thus causing them to suffer from diseases. As many as 23 respondents between the ages of 21 and 30 said they have health needs, while 12 respondents said they didn't. A total of 25 respondents between the ages of 31 and

Table 6: Age and health needs of the community

\begin{tabular}{lccc}
\hline \multicolumn{1}{c}{ Age (Years) } & \multicolumn{2}{c}{ Health Needs } & Total \\
& No & Yes & \\
\hline $21-30$ & 12 & 23 & 35 \\
$31-40$ & 13 & 25 & 38 \\
$41-50$ & 10 & 27 & 37 \\
$51-60$ & 9 & 35 & 44 \\
61years and above & 10 & 31 & 41 \\
\hline Total & 54 & 141 & 195 \\
\hline
\end{tabular}

Source: Field Survey, 2017 
40 have health needs, while 13 respondents didn't, and 27 respondents between the ages of 41 and 50 said they have health needs, while 10 respondents said they didn't. A total of 35 respondents between the ages of 51 and 60 said they have health needs, and 9 respondents said they didn't, while 31 respondents between the ages of 61 years and above said they do have health needs, but 10 respondents said they didn't. The trend of the above table shows how health needs increases as age increases. This shows the impact of long-term exposure to cement dust and health needs.

\section{Water Pollution and its Diseases}

Cement dust has polluted the sources of water for the rural people of the Kalambaina community. As a result, they have been affected by illnesses as shown in Table 7 below.

Table 7 shows that $80(43.4 \%)$ respondents said they experienced stomach pain due to the polluted drinking water, while 63 (34.6\%) respondents suffered from diarrhoea and 52 $(22.0 \%)$ respondents suffered from both. This shows how cement dust from the activities of the cement industry in the villages of the Kalambaina community pollutes their sources of water. When cement dust meets water, hydroxides are formed, which affect the natural water's alkalinity. A fine layer of cement covers the surface of wells and ponds. The addition of salts of $\mathrm{Ca}, \mathrm{Na}, \mathrm{K}, \mathrm{Mg}$ as hydroxides sulfates and silicates affect the hardness of the water, which is subsequently responsible for the respiratory and gastrointestinal diseases in the area (Mishra, 1991).

Table 7: Types of sickness related to water pollution

\begin{tabular}{lcc}
\hline Sickness & No & $\begin{array}{c}\text { Percent } \\
\text { (\%) }\end{array}$ \\
\hline Stomach Pain & 80 & 43.4 \\
Diarrhoea & 63 & 34.6 \\
Both & 52 & 22.0 \\
\hline Total & 195 & 100.0 \\
\hline
\end{tabular}

Source: Field Survey, 2017
The intake of polluted water causes stomach aches. Other gastrointestinal system diseases caused by polluted water includes oral cavity, mechanical trauma, mucosal inflammation, loss of tooth surface, periodontal diseases, dental caries, dental abrasion, liver diffuse, swelling and proliferation of sinusoidal (hepatic) lining cells, sarcoid granulomas, perisinusoidal and portal fibrosis and hepatic lesions (Chung \& Pavord, 2008). This further shows the impacts of cement dust on the sources of water in the community, which causes diseases to the rural people.

\section{Preventive Methods against Cement Pollution}

Past researches on cement pollution made appraisals through the structure of condition and social effect. The activity period of a cement industry can be long and frequently keeps going as long as 50 years or more. There is potential for both positive and negative effects on the environmental, financial and health systems.

In order to limit the human health hazards due to cement dust emissions, the manufacturing managers are required to put in place the latest technology in their industries. The board systems and constant internet-based monitoring can routinely actualise the exercises that will encourage adherence to the discharge standards recommended under the pollution control enactment. Notwithstanding, actualising the innovative and administrative measures to control dust and different discharges, it is additionally important to give satisfactory individual respiratory defensive gears for the constantly exposed individuals.

While deciding on the location of houses and schools, new and upcoming cement industries should keep in mind the prevailing wind direction in the region. For example, if the predominant wind direction is southwest to northeast, the placement of schools and houses ideally need to be located either in the southwest, south or southeast of the cement plant. It should never ever be in the northeast direction. In addition, the houses and schools located in proximity to the cement industries should be 
designed with the aim of achieving zero in-house dust exposure. As children studying in schools situated near factories are particularly prone to cement dust exposure, the school buildings and rooms are required to be equipped with efficient and perpetually functioning dust capture devices (Merenu et al., 2007).

Houses and schools in industrial premises are also required to be isolated from the industrial production plants with robust greenbelts, plantation strips and shelterbelts. Tree species with high pollution tolerance indexes can be planted in several rows. For example, Mangifera indica and Moringa oleifera, among others. Among the herbaceous plants, Achyranthus aspera has an incredibly high air defilement flexibility properties. Making greenbelts requires some genuine vitality. In any case, progressions in planting development can create minute green spread within half a year to a year. The idea is to use 2.5 to 3 metre-tall saplings for planting. Likewise, stake planting for specific species that can be recouped from stem cuttings can bring about smart results (Vijai \& Deep, 2011).

Industries that train proactive revelation of status of discharges are seen to be progressively moral and ecologically dependable. The state offices in charge of authorisation of pollution control standards, governments, social activists, and the media have turned out to be progressively capable of making industries be responsible for the social, economic and natural consequences of their industries. Also, in order to help labourers and the community houses situated inside the industrial premises or those in proximity, industries must introduce a non-stop constant online emanation checking system in the production line, as well as five persistent electronic presentation sheets for such information for conspicuous spots of industrial premises, including at the processing industry entryways, schools and community-lodging provinces.

\section{Conclusion}

It is important to note that the people of the Kalambaina community have been suffering for a long period of time, with no intervention from either the government or the cement industry. Air pollutants released from the cement industry have caused health hazards, contamination of air, sources of water and their crop yields, which they depend on. The health problems found among the people are due to long exposure of cement dust generated in the study area, which is the contribution of the study scientifically. Proper environmental laws and social policies must be implemented by both the government and the cement industry to curb this menace and enhance environmental sustainability, thus, bringing about meaningful development to the community, which is the contribution of the study publicly. These will be sine-qua-non to the social injustices experienced by the rural people of the Kalambaina community.

\section{Acknowledgements}

The authors are grateful for the financial support provided by the MPOB-UKM Endowment Grant (Project Code: EP-2019-054) for the publication of this research paper. This transdisiplinary research is part of a dissertation that was submitted as partial fulfilment to meet requirements of the degree of Doctor of Philosophy at Universiti Kebangsaan Malaysia.

\section{References}

Agapito, D., Mendes, J., \& Valle, P. (2013). Exploring the conceptualization of the sensory dimension of tourist experiences. Journal of Destination Marketing \& Management, 2(2), 62-73.

Balmes, J. R., Fine, J. M., \& Sheppard, D. (1987). Symptomatic bronchoconstriction after short-term inhalation of sulphur dioxide. American Review of Respiratory Disease, 136(55), 1117-1121. 
Bateman, A. C., \& Carr, N. (2008). The flesh and bones of pathology E-Book. Elsevier Health Sciences.

Buchanan, M., \& Horwitz, C. (2010) Pollution and society. University of Michigan Retrieved 08 October, 2019, from www. umich.edu/ gs265/society/pollution.htm.

Clean Air for Europe (CAFÉ). (2005). Programme: Towards a Thematic Strategy for Air Quality. Retrieved 06v August, 2019, from https://ec.europa.eu/environment/ archives/cafe/general/keydocs.htm.

Chung, K. F., \& Pavord, I. D. (2008). Prevalence, pathogenesis and causes of chronic Cough. Lancet, 371(9621),1364-74.

David, Z. M. D., \& David, R. E. (2010). Medline Plus. University of Washington School of Medicine, Seattle Washington, USA.

Davis, D. (2002). When smoke ran like water: Tales of environmental deception and the battle against pollution. Basic Books.

Efe, S. I. (2005). Urban effects on precipitation amount, distribution and rainwater quality in Warri Metropolis. Delta State, Nigeria: Delta State University Abraka.

Epa.gov. (2006). Retrieved 10 June, 2019, from http://www.epa.gov/ebtpages/airpollutants. $\mathrm{html}$.

Epa.gov. (2014). Retrieved 15 June, 2019, from http://www.epa.gov/ebtpages/airpollutants. html.

European Environment Agency. (2018). Air Quality in Europe - 2018 report. file:/// Users/ yewwongchin/ Downloads/Air\%20 quality\%202018\%20-\%20TH-AL-18-013EN-N.pdf, [accessed 20 April 2019].

Farnsworth, C. H. (1990). Report of World Bank on Poverty. New York, USA: Oxford University Press.

Gardner, G., Assadourian, E., \& Sarin, R. (2004). The state of consumption today. State of the World, 3-21.
Goldsobel, A., \& Chipps, B. E. (2010). Cough in the paediatric population. The Journal of Pediatrics, 156(3), 352-8. PubMed.

Gopinath, K. (2018) Studies on particulate matter in ambient air of urban Mangalore. [Ph.D. Dissertation. National Institute of Technology Karnataka, Surathkal, Mangolare]. 165pp.

Hughes, M., Kroechler, C. J., \& Vander, Z. J. W. (1999). Sociology: The core (5 $5^{\text {th }}$ ed.). New York: McGraw- Hill College. 253pp.

Kagawa, J. (1985). Evaluation of biological significance of nitrogen oxides exposure. Journal of Experimental and Clinical Medicine, 10(4), 348-353.

Kampa, M., \& Castañas, E. (2008). Human health effects of air pollution. Environmental Pollution, 151(2), 362-367.

Krewski, D., Burnett, R. T., Pope, C. A., Rainham, D., Calle, E. E., Thurston, G. D., $\&$ Thun, M. J. (2004). Mortality and longterm exposure to ambient air pollution: Ongoing analyses based on the American cancer society cohort. Journal of Toxicology and Environmental Health, A(68), 13-14.

Laswell, H. (1936) Politics: Who gets what, when and how? New York: McGraw-Hill.

Livernash, R., \& Rodenburg, E. (1998). Population change. Population Bulletin, 53(1), 35-38.

Liu, L., \& Zhang, J. (2009). Ambient air pollution and children's lung function in China. Environment International, 35(1), 178-186.

Mannucci, P. M., Harari, S., \& Franchini, M. (2019). Novel evidence for a greater burden of ambient air pollution on cardiovascular disease. Haematologica, 104(12), 23492357.

Martínez-Bravo, M., \& Martínez-del-Río, J. (2020). Urban pollution and emission reduction. Sustainable Cities and Communities, 905-915. 
Merenu, I. A., Mojiminiyi, F. B. O., Njoku, C. H., \& Ibrahim, M. T. O. (2007). The effect of chronic cement dust exposure on lung function of cement factory workers in Sokoto Nigeria. African Journal of Biomedical Research, 10, 139-43.

Mishra, G. P. (1991). Impact of industrial pollution from a cement factory on water quality parameters at Kymore. Environment and Ecology. Kalyani, 9(4), 876-880.

Muhammad, M. B., Rahimah, A., \& Vivien, W. C. Y. (2018). The effects of air pollution on socio-economic activities in Sokoto state, Nigeria. International Journal of Engineering and Technology. 7(3.21), 513-516. United Arab Emirates: Science Publishing Corporation Inc.

Muhammad, M. B., Rahimah, A., \& Vivien, W. C. Y. (2018). Socio-economic effects of industrialization in the society. International Journal of Environment, Ecology, Family and Urban Studies (IJEEFUS). 8(4), 23-30. India: TJPRC Pvt. Ltd.

National Geographic. (2002) "A World Transformed". National Geographic (September):Map.

National Population Commission. (2006). Population and housing census. Abuja, Nigeria.

Okecha, S.A. (2000). Pollution and conservation of Nigeria's environment. Ekpoma: T' Afriqu Inter ass W.A.

Ossai, E. K. et al. (1999). Pollution problems and environmental effects of chemicals, In Ekechi (Ed.), Reading in general studies: History and philosophy of Science (pp 8386). Abraka: General Studies Dept. Pub.

Pope, C. A., Burnett, R. T., Thun, M. J., Calle, E. E., Krewski, D., Ito, K., \& Thurston, G. D. (2002). Lung cancer, cardiopulmonary mortality, and long-term exposure to fine particulate air pollution. Journal of the
American Medical Association, 287(9), 1132-1141.

Rani, B., Singh, U., \& Maheshwari, R. (2011). Menace of air pollution worldwide. Advances in Biological Research, 2(1), 1-22.

Sokoto Cement Processing Unit. (2019). Sokoto Cement Company of Nigeria (Unpublished).

Siegrist, J. (2000). The social causation of health and illness. In Albrecht, G. L., Fitzpatrick, R., \& Scrimson, S. C. (Eds.), The handbook of social studies in health and medicine. London: Sage.

The Guardian. (2008). Retrieved 13 August 2019, from http://www.guardian.co.uk/ society/2008/apr/15/health.

Vijai, S. S., \& Deep, N. P. (2011). Human health risk due to Cement Dust Exposure PolicyBrief. Climate Change and CDM Cell, Rajasthan State Pollution Control Board, India.

Wakeji Clinic Records. (2019). Wamakko LGA, Sokoto State (Unpublished).

WHO Member State. (2004). Retrieved 15 July 2019, from http://www.who.int/entity/ quantifyingehimpacts/country profileseb Countryprofilesebd.xls.

Woodard, F. (2001). Industrial waste treatment handbook. USA: Butterworth-Heinemann.

Valavanidis, A., Fiotakis, K., \& Vlachogianni, T. (2008). Airborne particulate matter and human health: Toxicological assessment and importance of size and composition of particles for oxidative damage and carcinogenic mechanisms. Journal of Environmental Science and Health Care. Environment and Carcinogenic Ecotoxicology Review, 26(4), 339-62.

Yhdego. M. (1992). Epidemiology of industrial environmental health in Tanzania. Environment International, 18(4), 381-387. 